\title{
APLIKASI PENGELOLAAN DATA AKADEMIK BERBASIS WEB PADA BADAN KOORDINASI TAMAN PENDIDIKAN AL-QUR'AN
}

\author{
Agus Setyawan $^{1}$, Noor Azmi Fachri Hauzan ${ }^{2}$ \\ ${ }^{1,2}$ Program Studi Sistem Informasi Fakultas Teknologi Informasi Universitas Serang Raya \\ Jl. Raya Cilegon-Serang Drangong Taktakan Kota Serang Banten Indonesia \\ ${ }^{1}$ agus.setyawan@ ${ }^{2}$ hotmail.com
noorazmifachri@gmail.com
}

\begin{abstract}
Abstrak - Lembaga pendidikan sebagai suatu wadah yang berfungsi sebagai tempat melaksanakan proses belajar-mengajar, pelatihan dan pengembangan terhadap anak didiknya, di era globalisasi ini diharapkan bisa mengikuti perkembangan ilmu pengetahuan. Badan Koordinasi Taman Pendidikan Al-Qur'an (BADKO TPQ) adalah sebuah lembaga yang menyelenggarakan pembinaan terhadap anak-anak untuk jenjang setara dengan SD kelas 1 dan 2. Permasalahan yang terjadi pada BADKO TPQ Kota Serang adalah kurangnya optimalisasi dalam mengolah data akademik karena masih menggunakan sistem pembukuan sehingga hal tersebut membuat banyak waktu yang terbuang. Dengan menggunakan aplikasi ini diharapkan dapat membantu sistem kinerja pada BADKO TPQ Kota Serang.Hasil dari penelitian ini adalah para pengurus BADKO TPQ Kota Serang merasa puas dengan pemakaian aplikasi yang dibuat. Diharapkan untuk penelitian mendatang aplikasi yang ada dapat berbasis android.
\end{abstract}

Kata Kunci : Badko TPQ Kota Serang, Website, Data Munaqosah

\section{PENDAHULUAN}

Lembaga pendidikan sebagai suatu wadah yang berfungsi sebagai tempat melaksanakan proses belajar-mengajar, pelatihan dan pengembangan terhadap anak didiknya, di era globalisasi ini diharapkan bisa mengikuti perkembangan ilmu pengetahuan dalam bidang teknologi informasi untuk menunjang kegiatan akademik seperti pengolahan data akademik ataupun dalam penyajian informasi akademik secara cepat, tepat, akurat dan berkualitas.

Badan Koordinasi Taman Pendidikan AlQur'an (BADKO TPQ) adalah sebuah lembaga yang menyelenggarakan pembinaan terhadap anakanak untuk jenjang setara dengan SD kelas 1 dan 2 yang dinamakan Taman Pendidikan Al-Qur`an (TPQ). Program unggulannya adalah pemberantasan buta huruf Al-Qur`an (PBHA) disertai pemahaman dasar-dasar keagamaan. Awal lahirnya BADKO terdorong dari lahirnya Peraturan Daerah Kab. Serang No. 1 Tahun 2006 Tentang Penyelenggaran Wajib Belajar Diniyah, yang setiap lulusan Sekolah Dasar (SD) harus memiliki Ijazah MDA atau setara dengan pendidikan keagamaan.

Permasalahan yang terjadi di BADKO TPQ Kota Serang adalah kinerja bagian Tata Usaha dalam menyimpan dan mengolah data akademis yang kurang maksimal karena masih menggunakan sistem pembukuan manual. Hal tersebut membuat banyak waktu yang terbuang. Begitupun saat ingin mencari data yang dibutuhkan, proses pencarian data tersebut memakan waktu yang tidak sebentar karena data yang ada tersusun kurang teratur. Selain itu ketika ada informasi mengenai kegiatan rutin dan pengumuman penting lainnya, TPQ-TPQ yang berada dinaungan BADKO TPQ Kota Serang merasa kesulitan dalam mencari informasi tersebut.

Berdasarkan dari permasalahan diatas, maka alternatif untuk mengatasi permasalahanpermasalahan tersebut adalah dibuatnya suatu aplikasi yang diharapkan dapat meringankan kinerja bagian Tata Usaha BADKO TPQ Kota Serang agar dapat lebih efektif dan efisien. Sehingga dapat meminimalisir waktu yang terbuang percuma. Begitupun informasi-informasi mengenai kegiatan rutin dan pengumuman yang berhubungan dengan BADKO TPQ Kota Serang dapat tersampaikan dengan mudah dan cepat untuk pihak-pihak yang membutuhkannya.

Sesuai penjelasan di atas, maka penulis dapat mengidentifikasi masalah yang berkaitan dengan aplikasi ini, yaitu: 
a. Penyimpanan masih menggunakan sistem pembukuan untuk menyimpan data murid dan guru sehingga data murid dan guru yang ada mudah rusak dan hilang.

b. Data murid dan guru yang berupa pembukuan mengakibatkan proses pencarian dan pengambilan data murid dan guru tersebut sulit sehingga membutuhkan waktu yang cukup lama dalam melakukan proses pencarian dan pengambilan data ketika dibutuhkan.

c. Tidak tersedianya wadah untuk mencari informasi akademis tentang agenda kegiatan dan pengumuman penting BADKO TPQ Kota Serang bagi para TPQ yang berada dibawah naungan BADKO TPQ Kota Serang.

Tujuan dan Manfaat Penelitian

Adapun tujuan dilakukan penelitain ini yaitu:

1. Penelitian ini bertujuan untuk mempermudah penyebaran informasi seputar kegiatan yang dilaksanakan BADKO TPQ Kota Serang.

2. Membantu pihak Tata Usaha BADKO TPQ Kota Serang dalam mengolah data-data yang bersifat akademik.

3. Meminimalisir terjadinya kehilangan serta kerusakan data atau dokumen-dokumen.

\section{METODOLOGI PENELITIAN}

A. Teknik Pengumpulan Data

Teknik pengumpulan data yang digunakan dalam penelitian ini adalah :

1) Metode Observasi. Metode observasi merupakan suatu cara pengumpulan data dengan pengamatan secara langsung dengan mendatangi lokasi dan melihat proses kerja yang berjalan terhadap objek yang sedang diteliti, dalam penelitian ini yang diteliti adalah BADKO TPQ Kota Serang.

2) Metode Wawancara. Metode wawancara yaitu pengumpulan data dengan mengadakan tanya jawab secara langsung terhadap pihak-pihak yang terkait di BADKO TPQ Kota Serang agar mendapatkan data yang valid tentang kondisi terkini dari BADKO TPQ Kota Serang serta beberapa permasalahan yang ada, lalu memetakan permasalahanpermasalahan tersebut dan setelah memahami dari berbagai permasalahan kemudian memilih satu masalah utama yang dijadikan dasar dalam melakukan penelitian ini. Permasalahan yang akan dijadikan dasar pada penelitian ini adalah mengenai data-data akademik.

3) Metode Kepustakaan. Teknik pengumpulan data dengan cara literature atau membaca buku-buku yang terkait dengan permasalahan dan juga sumbersumber lainnya seperti jurnal, publikasi ilmiah, skripsi dan artikel-artikel di internet yang berkaitan dengan permasalahan.

\section{B. Model Pengembangan Sistem}

Dalam perancangan penelitian menggunakan metode pengembangan waterfall. Model waterfall adalah model klasik yang bersifat sistematis, berurutan dalam membangun software.

a. Communication (Project Initiation \&

Requirements Gathering)

Sebelum memulai pekerjaan yang bersifat teknis, diperlukan adanya komunikasi demi memahami dan mencapai tujuan yang ingin dicapai. Komunikasi dalam penelitian ini dilakukan dengan Sekretaris BADKO TPQ Kota Serang Bapak Firman. Dari hasil komunikasi atau wawancara dengan Sekertaris BADKO, dapat dianalisis bersama permasalahan-permasalahan yang dihadapi oleh BADKO TPQ Kota Serang.

b. Planning (Estimating, Scheduling, Tracking)

Tahap berikutnya adalah tahapan perencanaan yang menjelaskan tentang estimasi tugastugas teknis yaitu pembuatan web yang akan dilakukan, resiko-resiko yang dapat terjadi dalam pembuatan web, sumber daya yang diperlukan dalam membuat sistem, produk kerja yang ingin dihasilkan yaitu sebuah web, penjadwalan kerja yang akan dilaksanakan, dalam pembuatan web dan tracking proses pengerjaan dalam pembuatan sistem. Perencanaan ini dibahas bersama Sekertaris BADKO TPQ Kota Serang Bapak Firman.

c. Modeling (Analysis \& Design)

Tahapan ini adalah tahap perancangan dan permodelan arsitektur sistem web yang berfokus pada perancangan struktur data, arsitektur software, tampilan interface, dan algoritma program. Pada tahap ini dibuatkannya UML (Unified Modeling Language) yang kemudian akan dipresentasikan kepada Bapak Firman selaku Sekertaris BADKO TPQ Kota Serang lebih memahami gambaran besar dari apa yang akan dikerjakan.

d. Construction (Code \& Test)

Tahapan Construction ini merupakan proses coding yang dilakukan untuk membuat web dengan menggunakan SublimeText dan bahasa pemprograman PHP. Setelah pengkodean selesai, dilakukan pengujian terhadap sistem dan juga kode yang sudah dibuat. Tujuannya untuk menemukan kesalahan yang mungkin terjadi untuk nantinya diperbaiki.

e. Deployment (Delivery, Support, Feedback) 
Tahapan Deployment merupakan tahapan implementasi software ke BADKO TPQ Kota Serang sebagai customer. Setelah web diimplementasikan, maka dapat dilakukan pemeliharaan software secara berkala, perbaikan software, evaluasi software, dan pengembangan software berdasarkan umpan balik yang diberikan agar sistem dapat tetap berjalan dan berkembang sesuai dengan fungsinya.

\section{HASIL DAN PEMBAHASAN}

A. Perancangan Sistem

Perancangan sistem menggambarkan bagaimana sebuah sistem dibentuk agar memberikan gambaran yang jelas kepada pemakai. Perangcangan sistem ini menggunakan UML (Unified Modeling Language) yang meliputi Use Case Models, Activity Diagram, Sequence Diagram dan Class Diagram.

\section{Use Case Diagram}

Use Case Diagram pada rancangan sistem aplikasi untuk Pengelolaan Akademik Berbasis Web Pada BADKO TPQ Kota Serang adalah sebagai berikut :

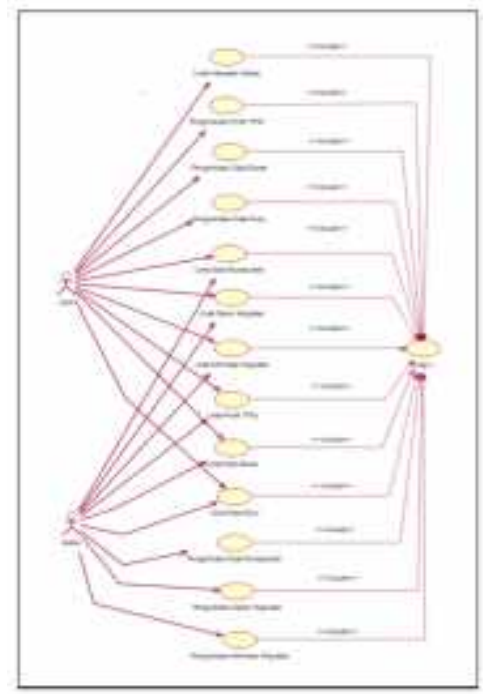

Gambar 1. Use Case

\section{Sequence Diagram}

Sequence Diagram menggambarkan interaksi antar objek di dalam dan di sekitar sistem berupa message yang digambarkan terhadap waktu.

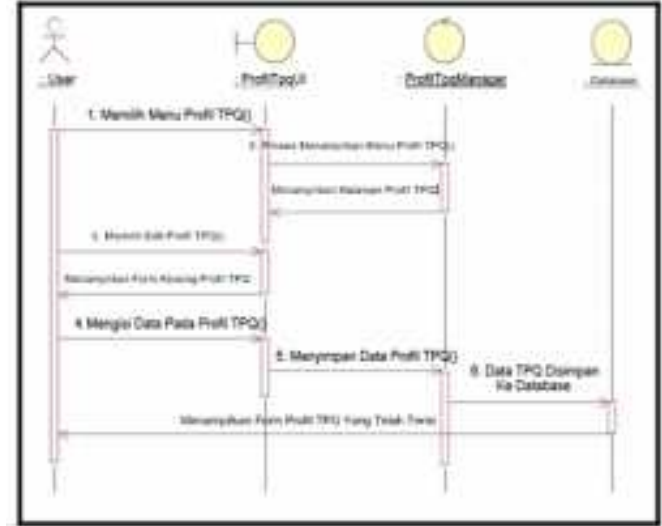

Gambar 2. Sequence Diagram Pengelolaan Profil TPQ

3. Class Diagram

Class Diagram menggambarkan struktur sistem dari segi pendefinisian class-class yang akan dibuat untuk membangun sistem. Class Diagram pada penelitian ini adalah :

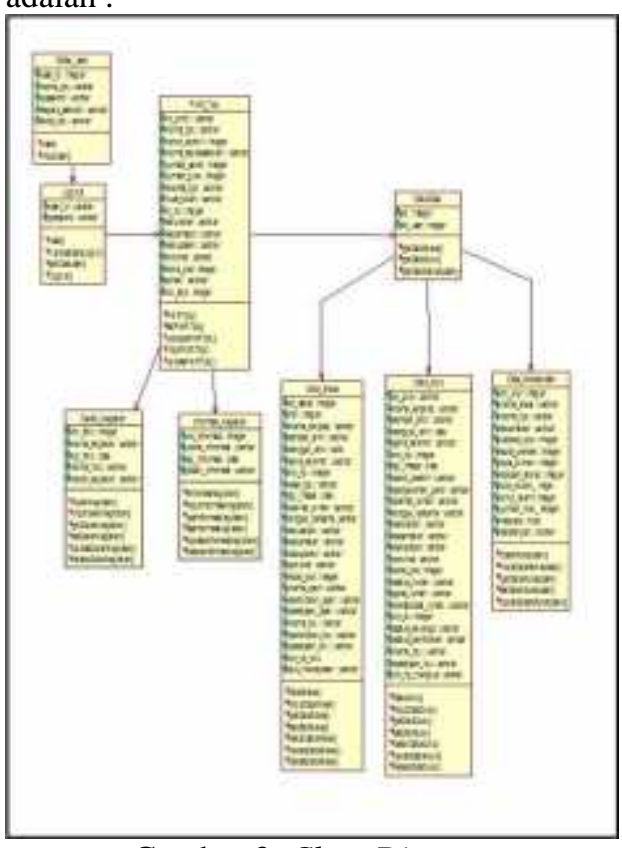

Gambar 3. Class Diagram

B. Implementasi Sistem

Berikut adalah tampilan (interface) dari sistem yang dibuat :

1. Halaman Utama

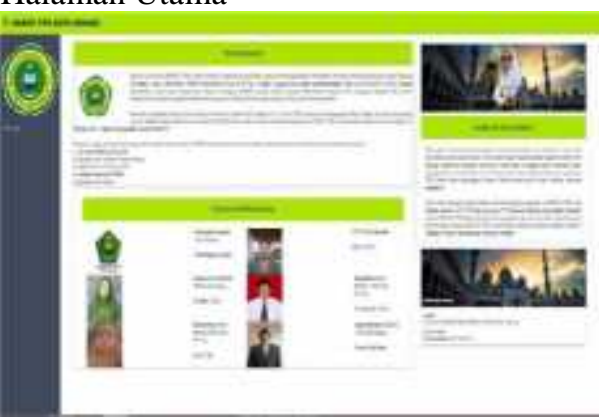


Gambar 4. Halaman Utama

2. Halaman Daftar User

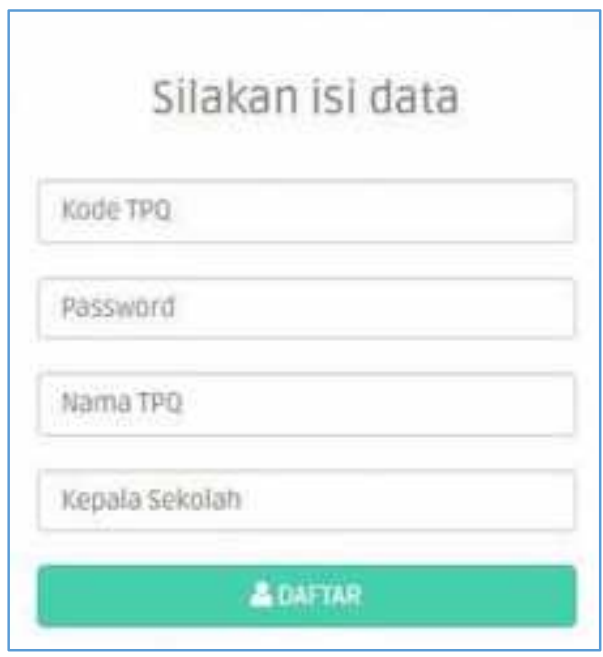

Gambar 5. Daftar User

3. Halaman Daftar Siswa

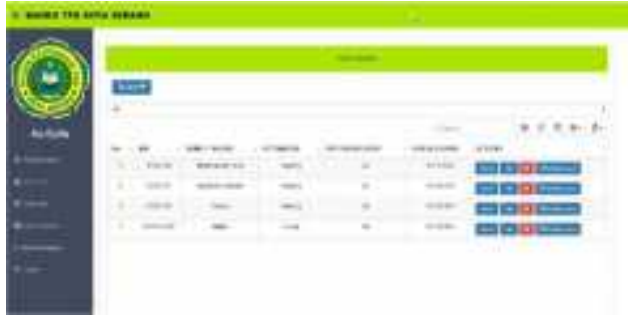

Gambar 6. Halaman Daftar Siswa

\section{KESIMPULAN}

Berdasarkan pembahasan yang telah dipaparkan di atas maka dapat di simpulkan bahwa penlitian ini :

1. Membangun aplikasi yang dapat digunakan untuk pengolahan data-data di BADKO TPQ Kota Serang dapat dilakukan dengan membuat aplikasi berbasis web karena mudah diakses dari manapun dan data relatif aman. Selain itu para pengguna aplikasi ini juga dapat memperoleh informasi informasi yang terkait tentang kegiatan yang dilaksanakan oleh BADKO TPQ Kota Serang.

2. Implementasi aplikasi pengelolaan data akademik berbasis web dalam membantu pihak BADKO TPQ Kota Serang dalam mengolah data-data yang ada dapat dilakukan dengan cara penggunaan langsung di BADKO TPQ Kota Serang dan unit-unit TPQ yang berada dibawah naungannya.

\section{REFERENSI}

[1] Al-Bahra (2013). Analisis dan Desain Sistem Informasi. Yogyakarta: Graha Ilmu.

[2] Djaelangkara, Recky T, Rizal Sengkley dan Oktavian A. Lantang. (2015). Perancangan Sistem Informasi Akademik Sekolah Berbasis Web Study Kasus Sekolah Menengah Atas Kristen 1 Tomohon. Jurnal Teknik Elektro Dan Komputer Vol 4 No 3 (2015). Tomohon: Univ Kristen Indonesia Tomohon.

[3] Galih, Sugono. (2016). Sejarah Dan Perkembangan HTML. [Online]. Tersedia: https://www.global-komputer.com/blog/artikel19-sejarah-danperkembangan-html.html [Diakses pada: 17 April 2018 Pukul 20.00 WIB]

[4] Hakim dan Musalini. (2004). Cara Cerdas Menguasai Layout, Desain dan Aplikasi Web. Jakarta: PT Elex Media Komputindo.

[5] Hasan, I. (2009). Pokok-Pokok Materi Statistik 1 (Statistik Deskriptif). Jakarta: PT.Bumi Aksara.

[6] Hidayatullah dan Kawistara. (2017). Pemprograman WEB Edisi Revisi. Bandung : Informatika Bandung.

[7] Homaidi, Ahmad. (2016), "Sistem Informasi Akademik Amik Ibrahimy Berbasis Web" Jurnal Ilmiah Informatika Vol 1 No 1 (2016). Situbondo: AMIK Ibrahimy.

[8] Imam, Nurul. (2013). Kelebihan Dan Kekurangan PHP. [Online]. Tersedia: https://www.nurulimam.com/2013/09/kelebiha n-kekurangan-php.html [Diakses pada: 17 April 2018 Pukul 20.00 WIB]

[9] Irwandi, Agus, Winda Sari dan Ulya Ulfah. (2015), Analisis Perancangan Sistem Informasi Nilai Siswa. Jurnal Sistem dan Teknologi Informasi Vol 1 No 1 (2015) . Banjarmasin: Politeknik Negeri Banjarmasin.

[10] Jayan. (2010). CSS untuk Orang Awam. Palembang: Maxikom.

[11] Lungan, R. (2006). Aplikasi Statistika dan Hitung Peluang. Yogyakarta: PenerbitGraha Ilmu.

[12] Mulyana, Wahyu Sabta. (2013). "Membangun Sistem Informasi Akademik Pada MTS. Mathla'ul Anwar Pusat Menes". Disertasi pada Universitas Serang Raya. Tidak Diterbitkan. 
[13] Pressman, R.S. 2015. Rekayasa Perangkat Lunak: Pendekatan Praktisi Buku I. Yogyakarta: Andi.

[14] Pramana, Hengky (2012). Aplikasi Inventory Berbasis Access 2003. Jakarta: PT. Elex Media Komputindo.

[15] Rivai dan Sukadi (2013). Pembuatan Website Profil Sekolah Menengah Kejuruan (SMK) Miftahul Huda Ngadirojo. Jurnal Indonesian Networking dan Security Vol 2 No 3.

[16] Rudianto, Arief (2011). Pemrograman Web Dinamis menggunakan PHP dan MySQL. Yogyakarta: Andi.

[17] Simarmata, Janner. (2010). Rekayasa WEB. Yogyakarta: Andi.

[18] Soetam, Rizky (2011). Konsep Dasar Rekayasa Perangkat Lunak. Jakarta: Prestasi Pustaka

[19] Sugiyono. (2003). Metode Penelitian Bisnis. Bandung: Alfabeta

[20] Sugiyono. (2013). Metode Penelitian Kuantitatif, Kualitatif Dan R\&D. Bandung : Alfabeta

[21] Susanto, Bob. (2016). Pengertian Aplikasi Menurut Para Ahli. [Online]. Tersedia: http://www.spengetahuan.com/2016/06/10pengertian-aplikasi-menurutpara-ahlilengkap.html [Diakses pada: 17 April 2018 Pukul 20.00 WIB]

[22] Sutabri, Tata (2012). Analisis Sistem Informasi. Yogyakarta: Andi.

[23] Wardani, Susy Kusuma. (2013). Sistem Informasi Pengolahan Data Nilai Siswa Berbasis Web Pada Sekolah Menengah Kejuruan (SMK) PGRI 1 Pacitan. Jurnal EPUB-Sistem Informasi Vol 1 No 1 (2013). Teknik Informatika, Fakultas Teknik Elektro Dan Informatika, Universitas Surakarta.
[24] Yuhefizar. (2012). Cara Mudah Membangun Website Interaktif Menggunakan CMS Joomla Edisi Revisi. Jakarta: PT. Elex Media Komputindo.

[25] Zamhari. (2016). Pengertian Akademik Beserta Contoh-Contoh Prestasinya. [Online]. Tersedia: http://www.academicindonesia.com/pengertia nakademik-beserta-contoh-contohprestasinya/ [Diakses pada: 17 April 2018 Pukul 20.00 WIB 